\title{
MODULAR COMPONENT POSITIONING ALONG THE BEAMLINE AXIS*
}

\author{
Kevin J. Beczek, Dean R. Walters, Jack M. Jagger \\ Advanced Photon Source, Argonne National Laboratory, Argonne IL 60439 USA
}

\begin{abstract}
In general, mechanical systems for particle accelerators are designed to remain stationary after they have been aligned. At the Advanced Photon Source (APS), a new device has been developed for the low-energy undulator test line (LEUTL), an experimental free-electron laser, that allows the components to be easily installed, removed, or exchanged without additional survey or alignment. A pair of high-precision linear guide rails fastened to a welded aluminum box beam provides the structure for this versatile and innovative method. The precision of this system exceeds $\pm 380 \mu \mathrm{m}$ along the beam axis and transverse to the beam. Design details and analysis are described as well as the present capabilities and those planned for the future.
\end{abstract}

\section{INTRODUCTION}

The concept of a modular and dynamic support structure grew out of the need to run experiments with components that could be rearranged or substituted as quickly and efficiently as possible, so as not to be inhibited by an excessively long construction phase. Although several alternatives presented themselves, it was decided that a rail and carriage system, aligned parallel to the beamline, would give the desired repeatability of transposition at the lowest cost, within the time required to fabricate it.

\section{DESIGN, ANALYSIS, AND FABRICATION}

\subsection{Structural Design Criteria}

Based upon the authors' experience with beamline construction, it was decided that the precision of the system needed to be within a $380-\mu \mathrm{m}$ radius from the beam centerline along the entire length of the rails. It soon became apparent that in order for the mounted devices to be able to meet the intended goal, the underlying supports would have to perform just as well. In other words, the precision had to be built in from the ground up. From this evolved a design with rails fastened to a box-beam-shaped stiffening girder. The girder would also need to be made of nonferrous materials to minimize any residual magnetic effects to the electromagnets sitting on top of it. Contrary to popular notion, however, yield strength under a static load alone as a design criteria

\footnotetext{
* Work supported by the U.S. Department of Energy, Office of Basic Energy Sciences, under Contract No. W-31-109-ENG-38.
}

would not suffice. Rather, the criteria focused primarily on the rigidity of the beam and secondly on a sufficiently high natural frequency, i.e., a frequency greater than 20 $\mathrm{Hz}$.

Deflection and vibration of beams has traditionally been based on classic mechanics theory. Applicable equations used in structural design can be readily found in publications by authorities such as Timoshenko [1] and Harris [2].

\subsection{Finite Element Analysis}

However, in recent years the use of finite element analysis software has made the typically iterative design process much more accurate and efficient. More to the point, the Pro/Engineer Mechanica [3] finite element program has been applied to a three-dimensional solid model of the girder to both improve the accuracy beyond the classic equations and give a better idea of the stress distribution and frequency response of a proposed geometry. Using this method, the girder design was optimized in a much shorter time than was previously possible.

The information from the analysis can be presented in several ways including contour map, color fringe plot, Cartesian coordinate graph, and animation. One of the more meaningful forms of display, particularly for stress distributions (Von Mises; i.e., distortion energy [4] ) is the fringe plot as shown in Figure 1. This displays the response of the girder to a combination load of $4.448 \mathrm{kN}$ (1000 lbs) and its own weight at the iteration of $3.260 \mathrm{kN}$ (733 lbs). Constraints were placed upon the beam, e.g., simulating flat surfaces $30.5 \mathrm{~cm}$ (12 in) from each end and bolting it down as opposed to simply having it supported.

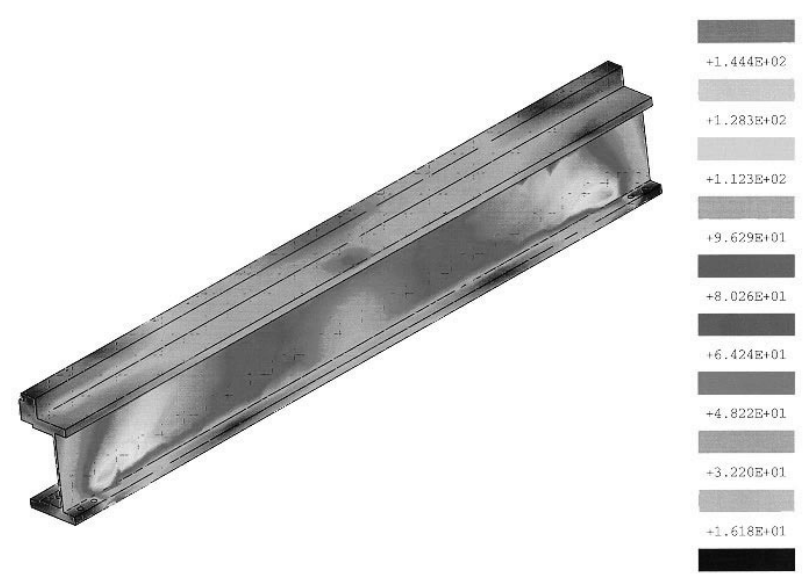

Figure 1: Girder distortion energy (color fringe plot) 
Notice that the author has taken advantage of symmetry and analyses only half of the girder, cutting it lengthwise. (If the applied load and center of mass were exactly centered along the span, it would be possible to further simplify this by cutting the said section in half again.) Similar studies were undertaken to examine the deflection of the beam. Extensive nodal analysis of the beam and support structure is planned to continue in the future. Results are shown in Table 1.

Table 1: FEA modeled girder characteristics

\begin{tabular}{|l|l|}
\hline $\begin{array}{l}\text { Maximum Deflection with } 4.448 \mathrm{kN}(1000 \mathrm{lbs}) \\
\text { load centered at midpoint of length }\end{array}$ & $\begin{array}{l}0.0178 \mathrm{~mm} \\
(0.0007 \mathrm{in})\end{array}$ \\
\hline First Harmonic (x-y plane) & In progress \\
\hline Total Weight & $3.260 \mathrm{kN}(733 \mathrm{lbs})$ \\
\hline Length & $3 \mathrm{~m}(118.1 \mathrm{in})$ \\
\hline Material & 6061-T6 aluminum \\
\hline
\end{tabular}

\subsection{Fabrication}

In an attempt to reduce costs and hasten the lead time, "off the shelf" items were used wherever possible. For example, the girder web uses the widest production aluminum c-channels available [5]. Prior to building the full-scale version, two 1.02-m-long prototypes of identical cross section were made. These were used to test the new carriage designs and to serve as staging platforms for installation on the large girder. Both large and small girders were intermittently (stitch) welded to minimize distortion. After welding they were vibration stress relieved, then the top and bottom surfaces were finish machined with a flycutter to within $0.381 \mathrm{~mm}$ flatness over the entire length. The carriage securing block of the girder was then machined to the same level of repeatability along the entire length. This feature allows carriages to be fastened securely to the girder in a manner similar to a conventional milling machine. Mating holes for the guide rails and securing block were drilled and tapped with threaded inserts screwed in place $[6,7,8]$.

\subsection{Girder Adjustment and Base}

The precise fabrication of the girder would be meaningless if there was no capability to adjust it when surveyed during installation. Consequently, the girder was bolted atop an adjustment mechanism that had been used successfully in the past at the APS. Two A36 structural steel plates became the "bed" for the girder and attachment points for two pairs of 11/4-inch 4140 finethreaded steel rods. These rods were then screwed into mating thrust bearings of heat-treated 420 stainless steel and coated with Dicronite (WS2 lamellar tungsten disulfide) [9] to ensure a highly lubricious surface. Opposing swivel-head clamps allow this assembly to move in the horizontal plane, and the rod and bearing allow it to move in the vertical direction. The entire mechanism rests on two industrial-grade and substantially gusseted machine tables also made from A36 structural steel and purchased from a local vender.

\subsection{Rail and Bearing Selection}

Perhaps one of the most crucial aspects of this design was the use of THK brand model GSR rails and linear bearings. In addition to having a low friction coefficient and an extremely high load capacity (approximately 0.003 and $25.9 \mathrm{kN}$ each, respectively [10]), the bearings can be installed or removed from the side of the mating guide rail (see Fig. 2). Notice that one bearing individually does not completely envelop the guide rail, yet when assembled in a mirror configuration, provides ample resistance to transverse loads, making the bearings and the objects upon them highly stable.

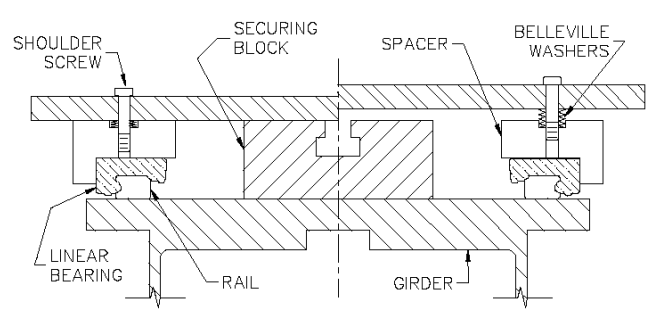

Figure 2: Cross-section of type "B" carriage (simplified for clarity)

\subsection{Carriage Design and Mechanics}

Straddling the securing block are several carriages, upon which the desired piece of beamline equipment rests; i.e., quadrupole magnets, corrector magnets, etc. Two types of carriages have been developed, each meeting the following design criteria: They must be removable from the bearings, and they must be able to be repeatedly raised and lowered onto the securing block to within a $380-\mu \mathrm{m}$ radius from the beam axis. However, each carriage differs with respect to precision and simplicity of the mechanism. The type "A" carriage uses a plate translating along the length of a set of dowel pins. A stack of Belleville springs with sufficient lifting force to raise the intended weight is inserted on the pins. When the plate is clear of the surface of the block, the carriage rests completely on the THK bearings and is then free to travel the length of the guide rail as far as the operator desires, or until it comes in contact with another carriage. A set of bolts flanking the pins allow the plate to lower onto the securing block, compressing the springs in the process. Once the plate has made contact with the machined surface of the securing block, it can be fastened down with a diamond-shaped rotary T-nut. The type "B" carriage, while operating on the same physical principle, uses fewer parts, with shoulder screws and coaxial Belleville springs replacing the dowel pin and bolts. 


\section{INHERENT VERSITILITY}

This support structure was designed from the start with the capability of being modified to suit the researcher's needs in the future. Installation of a mechanical or electromechanical transmission to move the components along the rails is certainly possible. Moreover, with the addition of a feedback device, the components might be controllable via computer to allow dynamic positioning or perhaps self-positioning. The entire structure can certainly be disassembled and rearranged to accommodate all of the aforementioned modifications.

\section{SUMMARY}

A modular method of positioning components along the beamline axis has been presented. A typical completed assembly is shown in Fig. 3. Although this is certainly not the only design that would meet our requirements, it is an innovative step forward in accelerator component support systems.

\section{ACKNOWELDGEMENTS}

The author wishes to thank John Noonan for his constant support, Frank DePaola and the many skilled tradesmen and technicians, especially Leonard Morrison, Bruce Hoster, Aaron Lopez, Mark Martens and Ron Kmak.
Also, kudos to Ms. Catherine Eyberger for her patience in editing this paper. Finally and most importantly, thanks to LEUTL chief engineer Dean Walters for his mentoring and seemingly tireless energy in helping make this project a success.

\section{REFERENCES}

[1] J. M. Gere and S. P. Timoshenko, Mechanics of Materials, second edition PWS Publishers, MA (1984).

[2] C. M. Harris and C. M. Crede, Shock and Vibration Handbook Vol. 1 Basic Theory, McGraw Hill, NY (1961).

[3] Pro/Engineer and Mechanica are registered trademarks of Parametric Technology Inc. Waltham, MA USA.

[4] G. E. Dieter, Mechanical Metallurgy, third edition McGraw Hill, NY (1986).

[5] Engineering Data for Aluminum Structures, third edition, the Aluminum Association, NY (1975).

[6] R. T. Reese, F. Cericola, T. L. Ernest, "Small Threaded Connections - Recommendations for Design and Testing," Report SAND91-1047, Sandia National Laboratories (1992).

[7] "Analysis of Pretensioned Bolted Joints Subject to Tensile Forces," Report ESDU-85021, Document ID $19890069141 \mathrm{~N}$ (89N71514), NASA Technical Reports (1985).

[8] A. W. Brisbane, "The Evaluation of Some Threaded Inserts," Report AD-A085070, Document ID 19800020217 N (80N28718), NASA Technical Reports (1979).

[9] Dicronite is a registered trademark of Lubrication Sciences Inc. San Jose, CA USA

[10] Linear Motion Systems Handbook No. 200, THK America, Schaumburg IL.

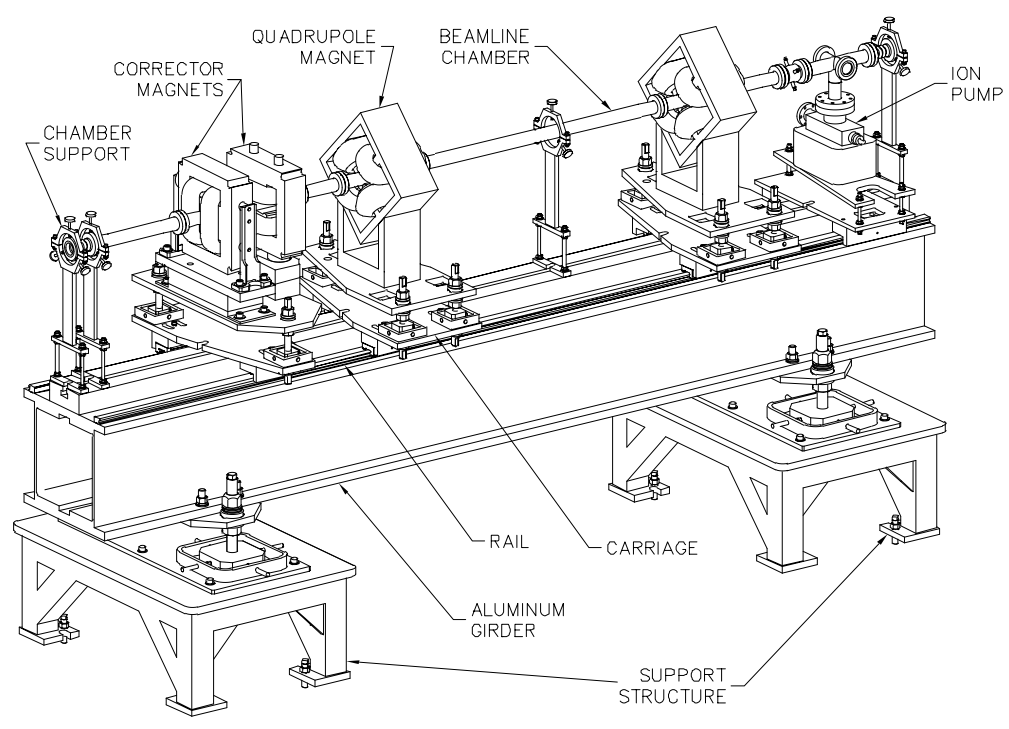

Figure 3: Beamline modular component station 